\title{
THE NEW TREND IN GYNECOLOGICAL THERAPY*
}

By George GellenorN, M.D., F.A.C.S., St. Louis, Mo.

$T$ was the name of this organization that decided my choice of a I subject. The very name suggests that close relationship of the sister sciences of gynecology and obstetrics from which, practically, all the progress of the last decades has sprung. This intimate kinship, this physiologic union of the two branches of medicine has repeatedly been assailed of late years and in several seats of learning it has actually been disrupted. In some of these instances, the sincere though mistaken idea may have prevailed that gynecology was nothing but a surgical specialty, while in others, personal and, therefore, all the more regrettable, motives seem to have been at work.

Be that as it may, it is a curious irony of fate that just at the moment when the general surgeons claim the gynecologic field as their own, gynecology has entered into a new phase of development where efforts are being made to replace surgical methods of treatment largely by nonsurgical means. It will be an easy and, I hope, an interesting matter to substantiate this statement by a brief survey of the situation.

Let us begin with eancer of the cervix-a surgical disease in the truest sense of the word. I will not again go over the ground that has been so well covered in today's discussions, nor will I present the statistics prepared for my own paper. These have been published elsewhere. ${ }^{1}$ In a deadly disease like cancer every single case which is permanently cured is a decided gain and a triumph of our surgical endeavors; thus the operative cures of approximately 25 per cent might well be a source of satisfaction to us. But when we contrast this figure with the number of all patients afficted with cancer, our achievements dwindle in importance.

For practical purposes the proposition amounts to this: Of 400 women who seek our aid for the relief of cancer of the cervix, barely 100 are actually and radically operated upon. ${ }^{2}$ The other 300 are hopeless cases; their doom is sealed even though we may inflict some sort of superfluous surgery upon them. Of the 100, on whom the radical abdominal operation is performed, about one-fourth die of the operation, about one-half die from recurrences, and about one-fourth are alive and well after five years. A material change in this sum total is hardly to be expected because the technic of the operation seems to have reached the zenith of perfection.

And now comes radiotherapy as an earnest competitor of the

* Read by invitation at the Thirty-fourth Annual Meeting of the American Association of Obstetricians, Gynecologists, and Abdominal Surgeons, St. Louis, Mo., September 20-22, 1921. 
surgical treatment in cervical cancer. To be sure, radiotherapy is still on probation. The first five-year period of observation has passed only recently and the percentage of radium cures is still a point or two below that of the surgical cures. But if we look upon these statistics in their true light, they will assume a new significance. The radium results reflect, to a large extent, the infaney of the new wethod which is just about to emerge from the crude empiricism of its initial stages. Better results, therefore, are bound to come in the future. Even now, one authority ${ }^{3}$ at least has already obtained results with radium that are in every way identical with those derived from surgery. Then, too, the cases treated with radium are on the whole more unfavorable than those subjected to operation. And to offset the slight difference in final results, there is a primary mortality from radium of 3 per cent as compared with the 20 or 25 per cent after operation.

If mon of vast experience and superior technical skill, like Doederlein and Bumm," eliminate surgery altogether in the treatment of uterine cancer and rely exclusively on radiotherapy, we should pause to think. As long as the subject is still a matter of discussion, the advocates of operation are, of course, justified in adhering to surgery; but the fact stands out in clear relief that surgery is no longer the only mode of attack and, unless all signs fail, the future of the treatment of uterine cancer belongs to radiotherapy,-at least until a biological method of treatment will have been discovered.

Personally, I had arrived at a formula which, until recently, seemed highly satisfactory to me. Inoperable and borderline cases were treated exclusively by a combination of radium and $x$-rays. Farly cases were operated upon by the radical abdominal method and received a preoperative treatment with radium and a postoperative treatment with $x$-rays. But I confess that my former confidence has deserted me, and at present my efforts are confined strictly to radiotherapy.

Another field of gynecology in which the therapy has, until recently, Jeen exclusively surgical, is that of fibroids. As we look back upon the brilliant development of the operations for fibroids and consider the steadily decreasing mortality and the benefits reaped by our patients, we can well understand that the feeling became established in the profession that the question of the best treatment was definitely ind satisfactorily settled.

The first reports on the effect of $x$-rays upon fibroids came as a complete surprise and met, in many quarters, with considerable incredulity; ut extensive confirmation came in a very short time, and today it nay be accepted as a fact that x-rays and radium check the hemorthages in about 98 per cent and reduce the size of the tumors in from 70 to 80 per cent of the cases. Further improvement may be expected 
from a more careful selection of the cases, the use of more powerful $x$-ray apparatus, and, perhaps, also from a judicious combination of radium and $x$-rays. At any rate, the surgical method of treatment, hitherto supreme, has now found a very strong rival in radiotherapy which can point to a mortality of 0 as against an average mortality of 3 to 5 per cent or even morc, aftcr surgical procedures.

Radiotherapy, however, cannot supplant surgery altogether. There are still enough cases of fibroids left in which an operation alone is indicated; but it is a significant fact that it is just the case with a poor surgical risk, the exsanguinated or the very fat woman, the patient with kidney or heart complications, that is particularly suited to, and benefited by, the new treatment. This is not the place to go into details as to indications and contraindications or a comparison of the complications following the two methods. The reader is referred to two previous publications. ${ }^{5,6}$ Suffice it to say that, approximately, only 30 per cent of the cases need operation while the overwhelming majority can be cured by nonsurgical means. Doederlein applied $\mathrm{x}$-rays in 222 cases of fibroids and used the knife in 91 others in the same period of time. Kelly used radium in 210 cases and operated on 45 .

The treatment of ehronic inflammations in the pelvis, particularly those of gonorrheal origin, forms one of the most changing and inter. esting chapters of gynecologic therapy. We have all witnessed and participated in these changes. It did not take long to realize that the so-called conservative treatment, that is, rest in bed, douches, tampons, and the like, only served to hasten the transition from the subacute to the chronic stage, and that an operation was required to bring about a cure. The surgical treatment itself underwent a long and varied evolution within the memory of most of us. At first satisfied with removing only the affected tube, we soon learned that the apparently healthy tube of the other side quite regularly developed into a pyosalpinx and demanded a second operation. Then, the persistence of the inflammation in the interstitial portions of the tubes required deep excisions of the uterine horns. And yet, the patients continued to complain of symptoms that arose from the uterus and did not eease until that organ was eliminated. To reduce this dreary train of operations, Beuttner, of Switzerland, devised an operation which was sponsored by Polak, in this country, and revived by Bell, in England, and consisted of the removal of both adnexa and a part of the uterus. Other operators believed that an ascending gonorrhea in the female was, in a way, an incurable discasc and, following the lead of Schauta and Landau, extirpated the entire uterus with both adnexa. Whatever method was adopted, it ultimately mutilated and unsexed the patient; and, as the disease occurs only in the reproductive age and is found more often in persons young in years, even the most successful outcome of our opera- 
tions could not possibly fill us with wholehearted satisfaction. It was Just this state of mind that induced many of us to attempt more conserving operations, such as injecting the tubes with some antiseptic fuid, splitting and draining them, etc., but you all know that these measures ended in signal failures.

More recently, however, a determined effort is being made to attack gonorrhea of the internal genitals by nonoperative means. Two novel methods have thus far been proposed. The first of these originated with Van de Velde, ${ }^{7}$ of Holland, who started from the familiar observation that the approaching menstruation exerts an untoward influence upon an acute salpingo-oophoritis. The inflammatory process, which above all else requires rest and protection, is stirred up by the cyclie changes in the ovaries and the resulting phenomena in the pelvic organs. In these cases, Van de Velde applied radium and $\mathrm{x}$-rays alone or combined and claims to have produced a "temporary" castration. The ovarian function was suppressed for from several months to one and one-half years; there was no exacerbation of the inflammation but Sever and other symptoms subsided, and complete cure could be brought about by a simple absorbent therapy. Similarly good results were obtained in cases of chronic recurrent adnexal inflammation.

The second method is the adoption of foreign protein therapy in gynecology of which the vaccine therapy was an early though ineffivient forerunner. By the introduction of foreign proteins, the protoplasm of the cells is stimulated to greater activity and the afflicted organs are, thereby, enabled to restore themselves to normal condivions. This, at least, is the theoretical explanation of the astounding results observed after the intramuscular or intravenous injections of milk or casein. A very recent article by Zill ${ }^{\text {s }}$ includes a report of 90 cases of large adnexal tumors treated in this manner for several weeks. of these 90 cases, 59 were cured completely, that is, the palpatory findings were perfeetly normal; 27 were improved, in that there was still a slight thickening of the adnexa, but the subjective well being of the patients was unimpaired; and only in four instances there was no improvement.

A very similar rationale underlies the treatment of ascending gonorrhea by means of injections of turpentine. This substance deposited in the subfascial tissues, produces a reaction which sets free homologous proteins, and these, in turn, are apt to activate the protoplasm of the cells of the inflamed structures. A dimination, and even disappearance, of the adnexal tumors has been claimed in a large percentage of the cases thus treated." ${ }^{9}$ It is not surprising that a number of wuthors ${ }^{11}$ have failed to observe such satisfactory results, for all these efforts of treating an ascending gonorrhea are still in an experimental stage; but they are highly promising and indicative of the present nonoperative trend in gynecologic therapy. Their final success would 
confer a blessing upon our patients whom we can cure by operation only at the expense of their genital function.

The abuse of the curette has been a much discussed evil, and the attempts at restricting this favorite instrument to its legitimate use in abortion, polyps, and, for diagnostic purposes, in cancer, have been numerous. We have now advanced far enoùgh into a better appreciation of the pathologic physiology of the female genital organs to know that dysmenorrhea and sterility very rarely require curettage. The profuse hemorrhages of adolescence, once the indication for repeated curettages, are now explained by endocrine disturbances and treated accordingly. As we learn to recognize a syphilitic metrorrhagia, we shall have no need for surgical treatment in cases of this kind. Uterine discharges of any kind used to call, automatically as it were, for the curette while today this instrument would be the very last thing an up-to-date gynecologist would consider in the treatment of this most common of all symptoms.

Another illustration. About a year ago I demonstrated before the St. Louis Medical Society the amazing effect of radium upon condylomata acuminata, and since then two papers have appeared reporting the same results with $x$-rays. ${ }^{12}$ All along the line then, we see, today, a tendency to replace surgical means by nonoperative means in the treatment of gynecologic affections.

But the factor that promises to do more than any other towards reducing the need for surgical intervention, is the product, the very child of that much maligned and wantonly disturbed union of obstetrics and gynecology-preventive obstetrics. It mattered little to the midwife of whatever sex, whether or not the cervix was torn in delivery as long as the bleeding was not excessive. It was the gynecologist with obstetric training and obstetric practice who realized the relations of cervical lacerations to subinvolution and its sequels, and their possible bearing upon cancer, and who insisted upon the necessary care in applying forceps. Neither did the midwife pay much attention to the position of the uterus four or six weeks after confinement; and again, it was the gynecologist who recognized that more than 75 per cent of all displacements occur after labor, and that these may be prevented by the proper hygiene of the puerperium or cured by the temporary use of pessaries.

I trust that nothing that has been said in these pages, will be misinterpreted as a disparagement of surgery, its brilliant progress, or its marvelous results. Any such thought would ill befit one who himself is a gynecologic surgeon. But I take it that our ultimate object is the cure of the patient, not the specific method by which we arrive at our goal, and it seems to me that, as far as our present attitude goes, this ultimate object is attainable in a large percentage of the cases by nonoperative means. 
It is, therefore, not illogical to suggest, at this time, a revision of our previous therapentic conceptions and to point to the necessity of a recasting of our fundamentals of treatment. Tt may, then, be seen that gynecology is, after all, not an exclusively surgical specialty, that with all the tremendous importance and value of surgical treatment, it is neither the only nor even the most important means at our disposal.

When a business house takes over another business concern, an inventory is made prior to the transfer. You may say that such stock should have been taken before gynecology was bound over to surgery, Precisely; but since the transaction seems to have taken place without such a procedure, it might be well to provide an inventory post festum, so as to have it on hand in the future if a readjustment should be under discussion. It may be that gynecology will revert from the security of present nonoperative gains to former surgical methods; but this is highly improbable because the present status of affairs indicates, to my mind, a higher phase of development. It may also be that gynecology in its present form and with a growing leaning towards nonoperative lines, will not appear as attractive to surgery as it lias seemed in the past, so that the realignment of gynecology and obsteties will meet with less opposition.

\section{BIBLIOGRAPHY}

(3) Gellhorn:" Tonr. of Radiology, 1921, ii, 23. (2) Tantor: Tr. Am. Gynee. Soc., 1912, xxxvii, 314. (3) Kehrer:' Tr. Gexman Gynec. Soc, 1920. (4) Doederlein and Kroenig: Operative Gynäkologie, ed. 4, 1921, p. 574. (5) Gellhorn: AM. JoUR. OF OBST. AND GYNEC., 1921, i, 767. (6) Gellhom: Jour. Missouri State Med. Assn., 1921, xviii, 220. (7) Vur le Felde: Zentralbl. f. Gyuàk., 1920, xliv, 994. (8) Zill: München. med. Wehnschr, 1921, lxvii, 803. (9) Friedrich: Zen* tralbl. f. Gynäk., 1921, xlv, 353. (10) Somnenfeld: ibid., 686. (11) Kromenberg: ibid., 257. (12) Stein: Wien. klin. Wohnschr., 1921, xxxiv, 315.

METropoltTAN BUTLDING.

(For" disoussion, see p. 316.) 